\title{
COGNITIVE DYSFUNCTION IN CHILDREN WITH SLEEP DISORDERS
}

\author{
Luciane Bizari Coin de Carvalhoㅁ, Lucila Bizari Fernandes do Prado², \\ Luciana Silva ${ }^{3}$, Marilaine Medeiros de Almeida ${ }^{3}$, \\ Tatiana Almeida e Silva3 ${ }^{3}$ Célia Maria Alcântara Machado Vieira³ \\ Álvaro Nagib Atallah4 ${ }^{4}$ Gilmar Fernandes do Prado ${ }^{5}$
}

\begin{abstract}
Sleep is basic for physical and cognitive development and some studies have suggested that there may be an association between sleep disorders (SD) and cognitive dysfunction (CD) in children. Little is known, how ever, about SD and cognition in 7-10-year-old children, a fact that motivated the present study. Method: We applied an SD questionnaire in 1180 children, 547 with SD and 633 without SD (CG), to assess cognition with a screening test (Bender Visual Motor Gestalt Test - BT). Results. We observed a similar frequency of CD in the children with SD $(39 \%)$ and that ot the CG $(40 \%)$. The 8-year-old children with SD presented a lower prevalence of $C D$ than the $C G(S D=6 \%, n=6 ; C G=13 \%, n=16 ; p=0.04)$. Conclusion: The frequency of children with $\mathrm{CD}$ was equal in the study and control groups when considering the total sample (7- to 10-year-old children). In contrast to our expectations, the SD group of 8-year-old children presented a lower frequency of $C D$ than the control group.
\end{abstract}

KEY WORDS: sleep disorders, children and cognitive dysfunction.

\section{Disfunção cognitiva em crianças com distúrbios do sono}

RESUM 0 - 0 sono é fundamental no desenvolvimento físico e cognitivo, vários estudos na literatura sugerem haver associação entre distúrbio do sono (DS) e disfunões cognitivas (DC) em crianças. Pouco se sabe, no entanto, sobre DS e cognição na faixa etária de 7 a 10 anos, motivo porque empreendemos este estudo. Método: A plicamos um questionário de DS em 1180 crianças: 547 com DS e 633 sem DS (GC), avaliando-se cognição pelo Teste Gestáltico de Bender (TB). Resultados: Observamos proporção semelhante de $D C$ nas crianças com DS (39\%) e nas do GC $(40 \%)$. As crianças de 8 anos do DS apresentaram menor prevalência de DC do que as do $G C$ (DS=6\%, $n=6 ; G C=13 \%, n=16 ; p=0,04)$. Conclusão: A proporção de crianças com DC foi igual nos grupos estudo e controle quando consideramos a amostra total (crianças de 7 a 10 anos). Contrariando nossas expectativas, o grupo DS de 8 anos apresentou menos DC que o grupo controle.

PALAVRAS-CHAVE: distúrbios do sono, crianças e disfunção cognitiva.

Sleep is basic for the physical and cognitive development of children ${ }^{1}$, but studies about sleep disorders (SD) and their consequences in this age group are few and inconclusive. About 35 to $46 \%$ of school-age children and 20 to $25 \%$ of adolescents present some kind of SD. Twenty percent of schoolage children snore, suffer from daily fatigue and experience difficulty to sleep at least once a week, and $14 \%$ of them have a poor quality of sleep ${ }^{2}$. Attempts have been recently made to show a relation between SD and learning problems ${ }^{3}$ in children that present a poor quality of sleep, irregular bedtime schedules and fatigue during classes. Children without difficul- ties in waking up in the morning are more motivated during classes whereas children with sleep restriction present difficulty in abstract thinking and verbal creativity $4^{4}$. Children with fragmented sleep had lower perfomance in neurobehavioral tests ${ }^{5}$, those with lower sleep efficiency had a higher percentage of incorrect responses in working memory tasks ${ }^{6}$, and those with acute sleep restriction increased innatentive behaviors ${ }^{7}$.

Sleep breathing disorders are highly prevalent among children and have been suggested to reduce cognitive performance more intensely than other SD, affecting memory, attention and visuo-constructive ability-10. Academic performance

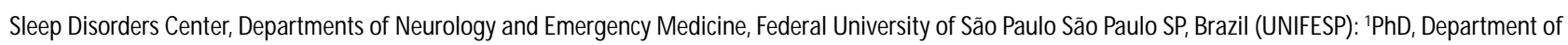
Neurology, Sleep Disorders Center, UNIFESP; 2M D, Department of Neurology, Sleep Disorders Center, UNIFESP; ${ }^{3}$ Department of Neurology, Sleep Disorders Center UNIFESP; ${ }^{4}$ M D, PhD, Brazilian Cochrane Center; ${ }^{5}$ M D, PhD, Departments of Neurology and Emergency Medicine, Sleep Disorders Center, UNIFESP. Supported by FAPESP 00/07513-3.

Received 1 April 2003, received in final form 17 September 2003. Accepted 4 November 2003.

Dr. Gilmar Fernandes do Prado - Rua Claudio Rossi 394 - 01547-000 São Paulo SP - Brazil. E-mail:gilmar.dmed@epm.br 
has been investigated in Brazil ${ }^{11}$, but little information exists about SD and cognitive dysfunction in Brazilian 7- to 10-yearold children ${ }^{12-13}$ and the few studies available involved inadequate samples, mainly because of the difficulty to study large samples in view of the fact that most tests for the assessment of cognitive function are difficult to apply.

On this basis, we undertook the present study evaluating the performance of SD children comparing with non-sleep disorder children by using a screening test for cognition.

\section{METHOD}

We studied 1180 children, 7- to 10 year-old, from August 1999 to June 2000, proceeding from 9 State Schools of Basic Education of the Region Center-South of the São Paulo City, Brazil. These schools had been drafted, among 35 possible ones, for representing each quarter of this region of which the university is a part. The study protocol $(447 / 00)$ was approved by the institutional review board of the Federal University of Sao Paulo, UNIFESP. The Consent was signed by the responsible Director of Education, the principals of the schools and the parents of the children.

About 5400 Questionnaires of Alterations of Sleep in Infancy (QASI), adapted for the Portuguese of Brazil, from Bruni et al. ${ }^{14}$ had been delivered. Until June 2000, 3612 questionnaires answered by the parents of the children had been returned and 589 were excluded because of incorrect filling in. For definitions of habits related to the normal sleep and SD, 3023 questionnaires were analyzed ${ }^{15}$. Six hundred and forty children presented witSD in the QASI ${ }^{14}$ and, they were all included for cognitive evaluation. We also elected randomically 640 normal children from a total of 2383 as a control group
(CG). We adopted a stratified procedure for randomization to pair for gender and age. A team of 12 trained psychologists had gone back to the schools and had assessed cognition with the screening test (Bender Visual M otor Gestalt Test - BT ${ }^{16-18}$ ), in 547 SD children and 633 CG group. The BT is aproppriated to screen cognition deficit because it can be rapidly applied (10 minutes) and has easy to understand instructions ${ }^{16-18}$. Fifty and three children of the group with SD and 7 children of the CG had not been tested because of absence during the days where the application proceeded by BT. The searching psychologist analyzed the BT and was unaware of which group the child belonged to: SD or CG. The SD group consisted of children with sleep breathing disorders (SBD), disorders of arousal (DA), difficulty in initiating and maintaining sleep (DIMS), disorders of sleepwake transition (DSWT), and daytime sleepiness (DSS). Children taking medicines, presenting psychiatric disorders (psychosis, autism) or genetic syndromes were not assessed. The diagnosis of cognitive dysfunction (CD) was analyzed according to the BT criterias ${ }^{16-18}$.

Statistical analyses: the data were analyzed in relation to the CG, i.e., by determining if the ratio of children with $C D$ in the SD group differed from that observed in the CG. We used the chi-square and Fisher tests, with the level of significance set at $p<0.05$. The explanation variables were: gender, age (7-, 8-, 9- and 10-yo), total sleep time $(<8 \mathrm{~h}$ and $>8 \mathrm{~h}$ ) and start time school (morning, afternoon).

\section{RESULTS}

The demographic data of this study population are show $\mathrm{n}$ in Tables 1 and 2. The SD group consisted of 79 children (14\%) with sleep breathing disorders, 454 children (83\%) with disorder of arousal, 16 children (3\%) with difficulty in initiating

Table 1. Distribution of the SD and CG children by gender, total sleep time (TST) and start time to school (STS).

\begin{tabular}{cccccccc}
\hline & & \multicolumn{2}{c}{ SD } & & & CG & \multicolumn{2}{c}{ Total } \\
& & $n$ & $\%$ & $n$ & $\%$ & $n$ & $\%$ \\
\hline Gender & Boys & 270 & 49 & 314 & 50 & 584 & 49 \\
& Girls & 277 & 51 & 319 & 50 & 596 & 51 \\
TST & $<8 \mathrm{~h}$ & 42 & 8 & 46 & 7 & 88 & 7 \\
& $>8 \mathrm{~h}$ & 491 & 92 & 578 & 93 & 1069 & 91 \\
\multirow{2}{*}{ STS } & Morning & 301 & 55 & 332 & 52 & 633 & 54 \\
& Affternon & 246 & 45 & 301 & 48 & 547 & 46 \\
\hline
\end{tabular}

Table 2. Distribution of SD and CG children by age (7, 8, 9 and 10 years-old).

\begin{tabular}{ccccccccccc}
\hline & \multicolumn{2}{c}{7 years } & \multicolumn{2}{c}{8 years } & \multicolumn{2}{c}{9 years } & \multicolumn{2}{c}{10 years } & \multicolumn{2}{c}{ Total } \\
\hline \multirow{2}{*}{ SD } & $n$ & $\%$ & $n$ & $\%$ & $n$ & $\%$ & $n$ & $\%$ & $n$ & $\%$ \\
CG & 161 & 29 & 143 & 26 & 144 & 26 & 99 & 16 & 547 & 46 \\
Total & 164 & 26 & 161 & 25 & 158 & 25 & 150 & 24 & 633 & 54 \\
\hline
\end{tabular}


Table 3. Distribution of cognitive dysfunction in sleep disorders group (sleep-breathing disorders - SBD; disorders of arousal - DA; difficulty in initiating and maintaining sleep - DIMS) and control group (CG) for all children, by gender, age (7, 8, 9, and 10 years old), total sleep time (<8h, $>8 h$ ) and by start time to school (STS-M: morning; STS-A: afternoon). Cognitive dysfunction did not differ significantly to each group pair.

\begin{tabular}{|c|c|c|c|c|c|c|c|c|c|c|c|c|}
\hline & \multicolumn{2}{|c|}{ SBD } & \multicolumn{2}{|c|}{ CG } & \multicolumn{2}{|c|}{$\mathrm{DA}$} & \multicolumn{2}{|c|}{ CG } & \multicolumn{2}{|c|}{ DIMS } & \multicolumn{2}{|c|}{ CG } \\
\hline & $n$ & $\%$ & $n$ & $\%$ & $n$ & $\%$ & $n$ & $\%$ & $n$ & $\%$ & $n$ & $\%$ \\
\hline Total & 79 & 34 & 633 & 40 & 454 & 39 & 726 & 40 & 16 & 50 & 1164 & 39 \\
\hline Boys & 48 & 31 & 314 & 39 & 218 & 38 & 366 & 39 & 7 & 43 & 577 & 38 \\
\hline Girls & 31 & 39 & 319 & 41 & 236 & 40 & 360 & 41 & 9 & 56 & 587 & 40 \\
\hline$<8 \mathrm{~h}$ & 4 & 50 & 47 & 36 & 32 & 41 & 56 & 21 & 1 & 0 & 87 & 40 \\
\hline$>8 \mathrm{~h}$ & 74 & 34 & 578 & 40 & 50 & 40 & 1019 & 39 & 410 & 39 & 659 & 40 \\
\hline STS-M & 48 & 40 & 332 & 37 & 249 & 37 & 384 & 38 & 6 & 33 & 627 & 38 \\
\hline STS-A & 31 & 26 & 301 & 43 & 205 & 41 & 342 & 42 & 10 & 60 & 537 & 41 \\
\hline 7 yo & 25 & 20 & 164 & 9 & 134 & 9 & 191 & 10 & 4 & 0 & 289 & 10 \\
\hline 8 yo & 24 & 25 & 161 & 36 & 116 & 30 & 188 & 34 & 2 & 0 & 302 & 32 \\
\hline 9 yo & 16 & 63 & 158 & 53 & 124 & 62 & 178 & 52 & 7 & 71 & 295 & 56 \\
\hline 10 yo & 14 & 43 & 150 & 66 & 80 & 65 & 169 & 66 & 3 & 100 & 246 & 65 \\
\hline
\end{tabular}

Table 4. Distribution of cognitive dysfunction in sleep disorders group (disorders of sleep-wake transition - DSWT; daytime sleepiness - DSS) and control group (CG) for all children, by gender, age (7, 8, 9, and 10 years old), total sleep time $(<8 h,>8 h)$ and by start time to school (STS-M: morning; STS-A: afternoon). Cognitive dysfunction did not differ significantly to each group pair.

\begin{tabular}{lcccccccc}
\hline & \multicolumn{2}{c}{ DSWT } & \multicolumn{2}{c}{ CG } & \multicolumn{2}{c}{ DSS } & \multicolumn{2}{c}{ CG } \\
& $n$ & $\%$ & $n$ & $\%$ & $n$ & $\%$ & $n$ & $\%$ \\
\hline total & 84 & 46 & 1096 & 39 & 61 & 44 & 1119 & 39 \\
boys & 43 & 47 & 541 & 38 & 37 & 46 & 547 & 38 \\
girls & 41 & 46 & 555 & 40 & 24 & 42 & 572 & 40 \\
$<8 \mathrm{~h}$ & 11 & 64 & 77 & 36 & 8 & 50 & 80 & 38 \\
$>8 \mathrm{~h}$ & 14 & 50 & 1055 & 39 & 70 & 44 & 999 & 39 \\
STS-M & 40 & 40 & 593 & 37 & 36 & 39 & 597 & 37 \\
STS-A & 44 & 52 & 503 & 40 & 25 & 52 & 522 & 41 \\
7 yo & 22 & 18 & 303 & 9 & 19 & 11 & 306 & 10 \\
8 yo & 17 & 29 & 287 & 32 & 14 & 21 & 290 & 33 \\
9 yo & 29 & 55 & 273 & 56 & 14 & 79 & 288 & 55 \\
10 yo & 16 & 88 & 233 & 64 & 14 & 79 & 235 & 65 \\
\hline
\end{tabular}

and maintaining of sleep 84 children (15\%) with disorder of the sleep-wake transition, and 61 children (11\%) with daytime sleepiness. There was no association among these sleep disorders and cognitive dysfunction (Tables 3 and 4). The grade and age variables were highly correlated and therefore were analyzed as single variable (Pearson Correlation $=0.946$; $p=0.01$ ).

The gender distribution of children with CD did not differ between the SD group and CG: 122 (48\%) were boys (Table 1). The age distribution of the children with $C D$ in the $S D$ group $(n=212)$ and in $C G(n=252)$ is shown in Table 2.

Fourteen SD children and 9 CG children did not report how much time they slept; of the 533 SD children and 624 CG children that provided this information, 491 (92\%) and 578 (93\%) children, respectively, slept more than 8 hours, and only 42 SD children and 46 CG children slept less than 8 hours, with no significant difference in the prevalence of $C D$ between the two groups ( $41 \%$ and $37 \%$, respectively).

Among the start time school - afternoon (STS-A) children, $246(45 \%)$ were from the SD group and $301(48 \%)$ from the CG. Of the start time school - morning (STS-M) children, 301 $(55 \%)$ were from the SD group and $332(52 \%)$ from the CG. The prevalence of $C D$ did not differ significantly between these groups ( $40 \%$ and $38 \%$ respectively). Among the 8 -year-old children with SD from STS-A, CD was more prevalent for the CG (CG $=13 \%, n=16 ; S D=6 \%, n=6 ; p=0.04 ; O R=0.31$; $95 \% \mathrm{Cl}=0.1$ to 0.9 ).

\section{DISCUSSION}

The children sleep questionnaires answered by the parents are criticized for their imprecision because the parents cannot always know what happens to the children, mainly if they sleep in another room and do not make noise or call their parents ${ }^{19}$. ${ }^{20}$. Besides, some adults do not perceive the sleep of their child 
as a "problem" and believe that sleep disorders are part of normal child development.

The questions about learning and cognitive skills depend on factors beyond those associated with SD, with an important influence of low income, children's work, lack of disease treatment, family disharmony, psychological problems and others, in addition to school difficulties. The complaints directly related to the mothers, such as the inability to impose limits to the children, anger roused by the children's demands and uncertainty about their mothering ability, produce anguish and anxiety in the child, which may manifest as sleep disorders ${ }^{20}$.

Paradoxically, in this study we observed a higher frequency of CD among 8-year-old CG children from STS-A. We could not find an explanation for the better BT performance of SD children; the fact that the child wakes up many times at night or has a poor quality of sleep may indirectly stimulate other neural pathways that can be used in cognitive functions, giving an impression of learning when there is only training or an adaptation to determined functions ${ }^{21-23}$. Phenomena such as the excessive number of arousals, anxiety, concern with experiences and a search for external references ${ }^{1}$ can be associated with functional activities predominantly depending on the right cerebral hemisphere, indirectly promoting a training for functions detected in the BT, masking the cognitive deficiency dependent on visuo-motor functions.

Literature studies on 7- to 10-year-old children suggest that these children present equal physical and psychological characteristics but, in some studies, the 8- year-old children presented different behaviors sometimes even opposite to the pattern of expected for this age $\mathrm{e}^{24-26}$. In our study, 7- to 8-yearold children differed amongst themselves and in relation to the other ages, and 9- to 10-year-old children showed a similar pattern of sleep and cognition.

It has also been shown that 8-year-old children present increased slow wave sleep, increased REM ${ }^{27}$ and many nightmares ${ }^{28}$, findings that have not yet been been associated with any specific etiology, and that do not reveal associated physical or psychological disorders, although the excessive number of arousals causes irregular secretion of growth hormone ${ }^{29}$.

With respect to cognitive development, we know that 8-yearold children differ from younger ones by being in the concrete operation period, i.e., they use egocentrism to understand relations and symbols, taking into account all the aspects of a situation, putting themselves in the place of others, perceiving the logic of the facts, but without the capacity to abstract ideas, which will only appear at about 12 years of age. They can, for example, perceive that dreams are inside their head and not actually present in the room; they know that dreams are unreal, but do not understand what they are, what they do and how they arrived there; they dominate the language and use it in the formation of groups, comparing themselves with their friends in terms of creativity and productivity. Sexuality is in the latency phase, although the children talk much about it and use it in their games as a determinant factor in the formation of rival groups ${ }^{1}$.

These physical, cognitive, psychological, and adaptive characteristics of 8-year-old children indicate that these children are passing through a phase of many changes and with special patterns specific for this age. Further separate investigation of this age is needed for a better understanding of the causes and consequences of this differentiation. As a whole, from 7- to 10-year-old children do not present cognitive dysfunction associated with sleep disorders.

Acknow ledgements - M rs Elletra Greene for the review translation and the Psychologist team: KV Serrano, AQM Alves, PHM Carneiro, MV Chucre, WH Oliveira, MI Bonavito, EL M at eVC Ronque.

\section{REFERENCES}

1. Papalia DE, Olds SW. O mundo da criança. São Paulo: McGraw-Hill, 1981.

2. Stein MA, Mendelsohn J, Obermeyer WH, Amromin J, Benca R. Sleep and behavior problems in school-age children. Pediatrics 2001;107:E60.

3. Meijer AM, Habekothe HT, Van Den Wittenboer GL. Time in bed, quality of sleep and school functioning of children. J Sleep Res 2000;9:145-153.

4. Randazzo AC, Muehlbach MJ, Schweitzer PK, Walsh JK. Cognitive function following acute sleep restriction in children ages 10-14. J Sleep Disor Res 1998;21:861-868.

5. Sadeh A, Gruber R, Raviv A. Sleep, neurobehavioral functioning, and behavior problems in school-age children. Child Dev 2002;73:405-417.

6. Steenari MR, Vuontela V, Paavonen EJ, Carlson S, Fjallberg M, Aronen E. Working memory and sleep in 6- to 13-year-old schoolchildren. J Am Acad Child Adolesc Psychiatry 2003;42:85-92.

7. Fallone G, Acebo C, Arnedt JT, Seifer R, Carskadon MA. Effects of acute sleep restriction on behavior, sustained attention, and response inhibition in children. Percept Mot Skills 2001;93:213-229.

8. Lojander J, Kajaste S, Maasilta P, Pertinen M. Cognitive function and treatment of obstructive sleep apnea syndrome. J Sleep Res 1999;8:71-76.

9. Decary A, Rouleau I, Montplaisir J. Cognitive deficits associated with sleep apnea syndrome: a proposed neuropsychological test battery. Sleep 2000;23:369-381.

10. Montgomery-Donws HE, Holbrook CR, Gozal D. Snoring prevalence among preschoolers at-risk for learning difficulties: a preliminary report. Sleep 2002;25:A230.

11. Rodrigues RND, Viegas CAA, Silva AAAA, Tavares P. Daytime sleepiness and academic performance in medical students. Arq Neuropsiquiatr 2002;60:6-11.

12. Carvalho LBC, Prado GF, Prado LBF, et al. Cognitive dysfunction in 7to 10-year-old sleep disorders children. Sleep 2001;24 (Suppl):362G.

13. Carvalho LBC, Prado LBF, Prado GF, et al. Cognitive dysfunction in 225 children 7- to 10-year-old with sleep disorders. Sleep 2002;25 (Suppl):316A.

14. Bruni O, Ottaviano S, Guideetti V, et al. The sleep disturbance scale for children (SDSC): childhood and adolescence. J Sleep Res 1996;5:251-261.

15. Silva TA, Carvalho LBC, Prado GF, et al. Sleep habits in Brazilian children 7- to 10-years-old. Sleep 2003;26(Suppl):A134.

16. Machado MCL. Uso do teste de Bender para avaliar a organização perceptivo-motora de escolares paulistas. Dissertação, Universidade Católica (PUC-SP). São Paulo,1978.

17. Koppitz EM. O Teste gestáltico de Bender para crianças. Trad. Rosaura N. Piccoli. Porto Alegre: Artes Médicas, 1987.

18. Lacks P. Bender Gestalt screening for brain dysfunction. New York: John Wiley \& Sons, 1999.

19. Aldridge Antal HM, LeBourgeois MK, Harsh J. The relationship between parental involvement and behavioral sleep quality in preschool aged children. Sleep 2002;25:A313.

20. Morrell JM. The role of maternal cognitions in infant sleep problems as assessed by a new instrument, the maternal cognitions about infant sleep questionnaire. J Child Psychol Psychiatry 1999;40:247-258.

21. Salorio CF, White DA, Piccirillo J, Duntley SP, Uhles ML. Learning, memory and executive control in individuals with obstructive sleep apnea syndrome. J Clin Exp Neuropsych 2002;23:93-100. 
22. Kim DJ, Lee HP, Kim MS, et al. The effect of total sleep deprivation on cognitive function in normal adult male subjects. Int J Neurosc 2001;109:127-137.

23. Drummond SP, Brown GG. The effects of total sleep deprivation on cerebral responses to cognitive performance. Neuropsychopharmacology 2001;25(Supp15):S68-73.

24. Broberg AG, Wessels H, Lamb ME, Hwang CP. Effects of day care on the development of cognitive abilities in 8-year-old: a longitudinal study. Dev Psychol 1997;33:62-69.

25. Pellizzer G, Hauert CA. Visuo-manual aiming movements in 6- to 10year-old children: evidence for an asymmetric and asynchronous development of information processes. Brain Cogn 1996;30:175-193.

26. Guerin N, Boulenguiez S, Reinberg A, Di Costanzo G, Guran P, Touitou Y. Weekly changes in psychophysiological variables of 8- to 10-yearold school girls. Chronobiology 1993;10:471-479.

27. Coble PA, Kupfer DJ, Reynolds III CR, Houck P. EEG Sleep of healthy children 6 to 12 years of age. In Guilleminault C (ed). Sleep and its disorders in children. New York: Raven Press, 1986.

28. Muris P, Merckelbach H, Gadet B, Moulaert V. Fears, worries, and scary dreams in 4- to 12-years-old children: their content, development pattern, and origins. J Clin Child Psychol 2000;29:43-52.

29. Grunstein RR. Hormonal and metabolic changes during sleep in children. In Loughlin GM, Carroll JL, Marcus CL (eds). Sleep and breathing in children, a developmental approach. New York: Marcel Dekker, 2000: 131-151. 